\title{
Regulation of the vascular extracellular superoxide dismutase by nitric oxide and exercise training
}

\author{
Tohru Fukai, Martin R. Siegfried, Masuko Ushio-Fukai, Yian Cheng, Georg Kojda, \\ and David G. Harrison
}

Division of Cardiology, Department of Medicine, Emory University School of Medicine and

the Atlanta Veterans Administration Hospital, Atlanta, Georgia, USA

Address correspondence to: Tohru Fukai, Division of Cardiology, Emory University School of Medicine, 1639 Pierce Drive, Woodruff Memorial Building 319, Atlanta, Georgia 30322, USA.

Phone: (404) 727-8905; Fax: (404) 727-3330; E-mail: tfukai@emory.edu.

Received for publication February 8, 2000, and accepted in revised form April 10, 2000.

\begin{abstract}
The bioactivity of endothelium-derived nitric oxide (NO) reflects its rates of production and of inactivation by superoxide $\left(\mathrm{O}_{2}{ }^{-}\right)$, a reactive species dismutated by extracellular superoxide dismutase (ecSOD). We have now examined the complementary hypothesis, namely that NO modulates ecSOD expression. The NO donor DETA-NO increased ecSOD expression in a time- and dosedependent manner in human aortic smooth muscle cells. This effect was prevented by the guanylate cyclase inhibitor ODQ and by the protein kinase G (PKG) inhibitor Rp-8-CPT-cGMP. Expression of ecSOD was also increased by 8 -bromo-cGMP, but not by 8-bromo-cAMP. Interestingly, the effect of NO on ecSOD expression was prevented by inhibition of the MAP kinase p38 but not of the MAP kinase kinase $\mathrm{p} 42 / 44$, suggesting that NO modulates ecSOD expression via cGMP/PKG and P38MAP kinase-dependent pathways, but not through p42/44MAP kinase. In aortas from mice lacking the endothelial nitric oxide synthase (eNOS), ecSOD was reduced more than twofold compared to controls. Treadmill exercise training increased eNOS and ecSOD expression in wild-type mice but had no effect on ecSOD expression in mice lacking eNOS, suggesting that this effect of exercise is meditated by endothelium-derived NO. Upregulation of ecSOD expression by NO may represent an important feed-forward mechanism whereby endothelial NO stimulates ecSOD expression in adjacent smooth muscle cells, thus preventing $\mathrm{O}_{2}{ }^{-{ }^{-}}$-mediated degradation of $\mathrm{NO}$ as it traverses between the two cell types.
\end{abstract}

J. Clin. Invest. 105:1631-1639 (2000).

\section{Introduction}

Nitric oxide (NO) exerts many antiatherogenic actions via vasodilation, as well as inhibition of platelet aggregation, smooth muscle cell proliferation, and leukocyte adhesion to endothelial cells in the vessel wall (1). In addition, it has become evident that several pathological conditions, including hypertension, atherosclerosis, and diabetes, are associated with increased vascular production of $\mathrm{O}_{2}{ }^{\bullet-}$. Because $\mathrm{O}_{2}{ }^{\bullet}$ and $\mathrm{NO} \mathrm{O}^{\bullet}$ both contain unpaired electrons in their outer orbitals, they undergo an extremely rapid, diffusion-limited radical/radical reaction, leading to formation of the peroxynitrite anion, a strong oxidant with potent biologic effects. Thus, controlling the amount of $\mathrm{O}_{2}{ }^{\bullet}$ is critically important for preserving $\mathrm{NO}^{\bullet}$ bioactivity in the vessel wall.

The superoxide dismutases (SODs) represent a major cellular defense against $\mathrm{O}_{2}{ }^{-}$and formation of peroxynitrite (2). Three isozymes of SOD have been identified, including a cytosolic copper/zinc-containing form $(\mathrm{Cu} / \mathrm{ZnSOD})$, a mitochondrial manganese form (MnSOD), and an extracellular isozyme (ecSOD), which is also a copper/zinc-containing enzyme. In the vessel wall, one third to one half of the total vascular SOD is the ecSOD (3). Human recombinant ecSOD, when administered exogenously, can reduce infarct size in pigs (4). Likewise, chimeric enzymes in which heparin-binding domains have been added to $\mathrm{Cu} / \mathrm{ZnSOD}$ to form mimics of ecSOD have been shown to reduce blood pressure in rats made hypertensive by angiotensin II (5). These findings suggest that ecSOD likely plays a major role in preventing the pathophysiological effects of $\mathrm{O}_{2}{ }^{--}$in the vasculature.

Physical exercise has been associated with a reduction in cardiovascular morbidity and mortality (6-8). One mechanism that may underlie this beneficial effect involves an upregulation of the endothelial NO synthase (eNOS), increasing local production of $\mathrm{NO}^{*}$ (9). Paradoxically, exercise also increases total body oxygen uptake, increasing production of reactive oxygen species (10). The manner in which the vasculature adapts to this oxidant stress remains unclear.

In view of the important role of SOD in modulation of NO bioactivity, we examined the hypothesis that NO itself might modulate ecSOD expression. We further studied signaling mechanisms involved in this process and sought to examine the physiological consequences of $\mathrm{NO}$ modulation of ecSOD during exercise training in mice. 


\section{Methods}

Studies of human aortic smooth muscle cells. Human aortic smooth muscle cells (HASMs) (Clonetics Corp., San Diego, California, USA) were cultured in Smooth Muscle Basal Medium (Clonetics Corp.) and 5\% FBS. Experiments were performed with $0.5 \%$ serum with no additives at passages 4-7. Expression of protein kinase G, which may decline in later cell passages (11), was confirmed in the cells used in these experiments by Western analysis (data not shown).

Animals studied. C57BL/6 mice were purchased from The Jackson Laboratories (Bar Harbor, Maine, USA) and maintained on regular chow for 1-2 months. Two strains of mice lacking the endothelial nitric oxide synthase (eNOS ${ }^{-/-}$mice) were also studied. Strain A, which referred to $\mathrm{NOS}^{-/-}$mice in which the exons encoding the NADPH ribose and adenine binding sites (amino acids 1010-1144) had been disrupted, were obtained from P.L. Huang (Massachusetts General Hospital, Boston, Massachusetts, USA) (12). Strain B eNOS ${ }^{-/-}$animals, in which exon 12 encoding calmodulin-binding site had been disrupted, were obtained from The Jackson Laboratories (13). Both strains had been backcrossed ten times to the $\mathrm{C} 57 \mathrm{BL} / 6$ strain.

Examination of ecSOD $m R N A$ and protein expression and aortic SOD activity. RNase protection assays for mRNA levels, Western analysis for protein expression, and analysis of aortic SOD activity were performed as described previously $(14,15)$. Nuclear run-on assays were carried out as described previously $(14,16)$, using ecSOD cDNA, GAPDH cDNA, and vector cDNA as probes. Equal amounts of these cDNA probes $(5 \mu \mathrm{g})$ and a GAPDH cDNA probes were slot blotted onto a
Zeta-Probe GT membrane (BioRad Laboratories Inc., Hercules, California, USA). Identical numbers of nuclei from control and DETA-NO-treated HASMs were used for preparation of nascent radiolabeled transcripts. Hybridization was performed for 36 hours at $65^{\circ} \mathrm{C}$. Signals were visualized by autoradiography, and densitometric values for the nascent ecSOD transcripts were normalized to the GAPDH signal.

Detection of p38MAP kinase phosphorylation by immunoblotting. Phospho p38MAP kinase was detected by Western analysis as we described previously (17). The blots were incubated for 1 hour with rabbit polyclonal phospho-specific p38 antibody (New England Biolabs Inc., Beverly, Massachusetts, USA) that detects p38MAP kinase only when activated by phosphorylation on TXY, at 1:2,000. After incubation with the secondary antibody (horseradish peroxidase-conjugated goat anti-rabbit antibody, 1:1,000) for 1 hour, positive-stained bands were detected by ehanced chemiluminescence.

Exercise training. Mice were exercise trained on a motorized rodent treadmill (Collins Rodent Treadmill, Braintree, Massachusetts, USA) at a speed of $15 \mathrm{~m} / \mathrm{min}$, for 30 minutes per day, 5 days per week for 3 weeks. To control for any nonexercise effects of treadmill running (handling, novel environment, noise, and vibration), a separate group of animals (sham exercise) were placed on the top of treadmill apparatus for an identical period. After 3 weeks of exercise or "sham" exercise, mouse aortas were harvested and Western analysis was performed as described previously here $(14,15)$.

Organoid cultures of mouse aorta. After dissection of adventitial tissue, and denudation of the endothelium, aortic segments were immersed in six-well dishes con- a

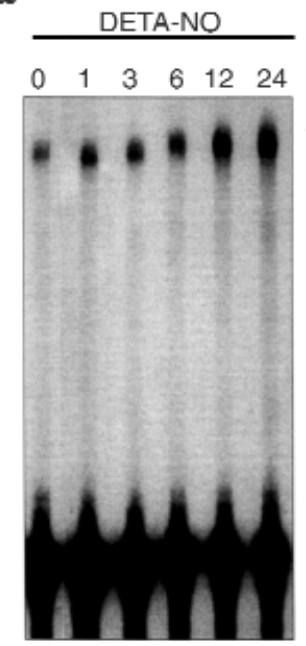

b

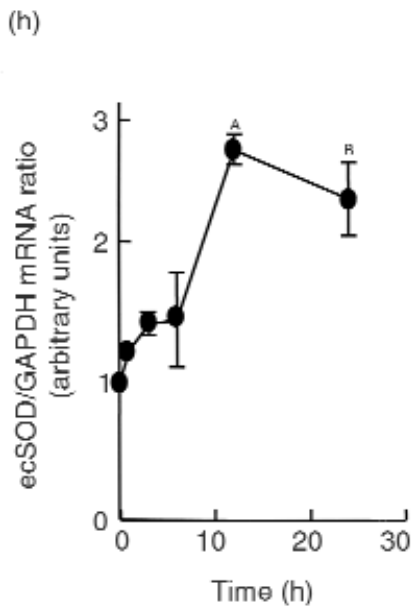

C

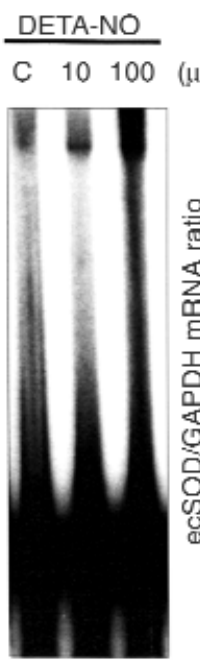

d

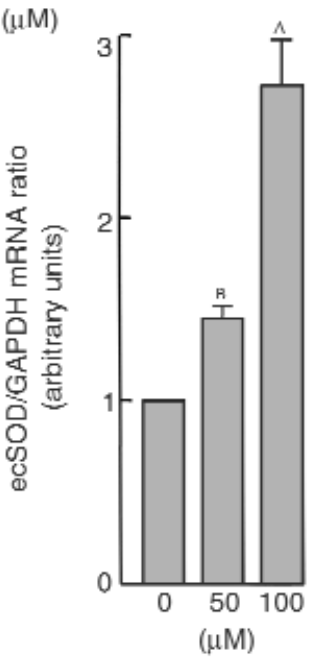

Figure 1

RNase protection assays showing time course ( $\mathbf{a}$ and $\mathbf{b})$ and dose dependence ( $\mathbf{c}$ and $\mathbf{d}$ ) of ecSOD mRNA expression in response to DETA$\mathrm{NO}$ in HASMs. HASMs (passages 4-8) were exposed to DETA-NO $(100 \mu \mathrm{M})$ for the times indicated (a and $\mathbf{b})$ and for the dose indicated at the 12 hour time point (c and $\mathbf{d}$ ). The levels of ecSOD mRNA levels were determined using RNase protection assays using human ecSOD and GAPDH riboprobes as an internal control. ( $\mathbf{a}$ and $\mathbf{c}$ ) Representative RNase protection assay. (b and $\mathbf{d}$ ) Mean data for three separate experiments. ${ }^{A} P<0.01 ;{ }^{B} P<0.05$ versus control cells. 

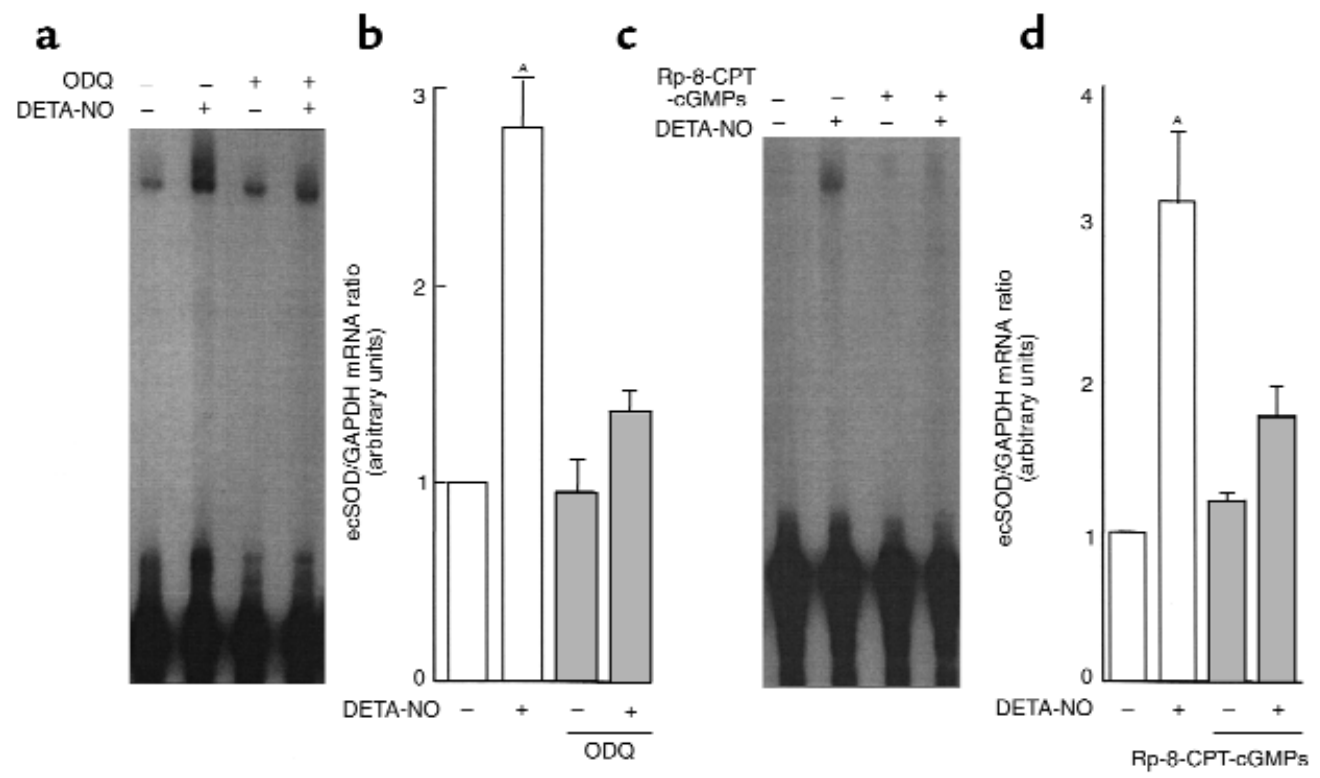

\section{Figure 2}

Effect of the guanylate cyclase inhibitor ODQ $(10 \mu \mathrm{M})$ and the PKG inhibitor RP-8CPT-cGMPs $(5 \mu \mathrm{M})$ on NO induction of ecSOD expression in HASMs. HASMs were exposed to DETA-NO $(100 \mu \mathrm{M})$ for 12 hours in the absence or presence of the various antagonists noted. (a and $\mathbf{c})$ Representative RNase protection assays. ( $b$ and $\mathbf{d}$ ) Mean data quantified by densitometry of immunoblots. The data are expressed as fold increases in ecSOD expression. Values are the mean \pm SE for three separate experiments. ${ }^{A} P<0.01$ versus control.

taining DMEM (GIBCO BRL, Gaithersburg, Maryland, USA), antibiotics $(100 \mathrm{U} / \mathrm{mL}$ penicillin and $100 \mathrm{mg} / \mathrm{L}$ streptomycin), and $0.1 \%$ calf serum, as described previously (14). The vessel segments were then maintained in a tissue culture incubator at $37^{\circ} \mathrm{C}$ and exposed to various experimental conditions for the times indicated.

Materials. Radiochemicals were purchased from DuPont Corp. (Boston, Massachusetts, USA) DETANO, Rp-8CPT-cGMPs, 8-bromo-cGMP, 8-bromocAMP, ODQ $(1 \mathrm{H}-[1,2,4]$ oxadiazolo[4,3-a]quinoxalin1-one) were from Alexis Corp. (San Diego, California, USA). SB203580, PD98059, and PD169316 were purchased from Calbiochem. All other reagents were purchased from Sigma Chemical Co. (St. Louis, Missouri, USA), except where specified. The polyclonal antibody for ecSOD detection has been described previously (14, 15). Other antibodies were obtained commercially, including anti-eNOS (Transduction Laboratories, Lexington, Kentucky, USA), anti-Cu/ZnSOD (BioDesign International, Kennebunk, Maine, USA), and antiphospho p38MAP kinase (New England Biolabs Inc., Beverly, Massachusetts, USA). Anti-rabbit IgG (BioRad Laboratories Inc.) was used as a secondary antibody. Data analysis and statistical evaluation. RNase protection assays and Western blots were analyzed by densitometry using NIH Image software (National Institutes of Health, Bethesda, Maryland, USA). For RNase protection assays, values were normalized to the GAPDH densitometry. In each of these cases, data for $\mathrm{NO}$ and other experimental conditions are expressed as a percent of control vessels studied in parallel. Values are expressed as mean \pm SEM. Comparisons were per- formed using $t$ tests and a Bonferroni correction for multiple comparisons where indicated. Values of $P<$ 0.05 were considered significant.

\section{Results}

Effect of NO on ecSOD expression in HASMs. To examine the direct effect of $\mathrm{NO}$ on ecSOD mRNA expression, we performed RNase protection assays in HASMs and used the NONOate DETA-NO as an NO donor. DETA-NO produced a time-dependent increase in ecSOD mRNA expression that was apparent at 4 hours and was maximal between 12 and 24 hours (Figure 1, a and b). DETA-NO also increased ecSOD mRNA dose dependently. The highest concentration of DETA-NO used $(100 \mu \mathrm{M})$ increased ecSOD expression by $2.7 \pm 0.3$ fold (Figure $1, \mathrm{c}$ and d). Because DETA-NO releases NO ${ }^{\bullet}$ over 12 hours, this concentration of DETA-NO corresponds to a release of approximately $2 \mathrm{nmol}$ of $\mathrm{NO}^{\bullet}$ per 10 seconds.

We next sought to investigate the signaling pathway responsible for the increase in ecSOD in response to NO* NO exerts cellular effects via both cyclic GMP-dependent (cGMP) and -independent mechanisms (18); however, in the case of its effect on expression of ecSOD, the effect seemed entirely cGMP dependent. The selective guanylate cyclase inhibitor (10 $\mu \mathrm{M}$ ODQ) and the protein kinase G (PKG) inhibitor (5 $\mu \mathrm{M}$ Rp-8-CPT-cGMP) completely blocked the effect of DETA-NO on ecSOD expression (Figure 2). In addition, the cGMP analogue, 8-bromo-cGMP $(100 \mu \mathrm{M})$ mimicked the effect of NO (Figure 3 , a and $b$ ). In contrast, cAMP analogue, 8-bromo-cAMP $(100 \mu \mathrm{M})$ had no effect on ecSOD expression (Figure $3 b$ ). 
a

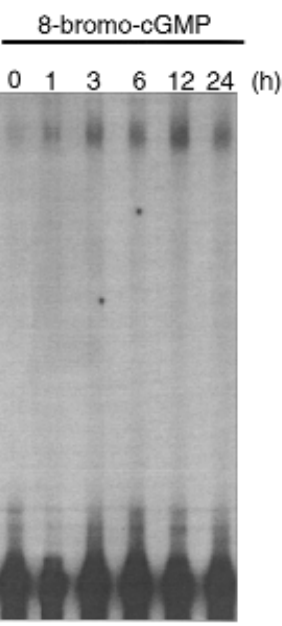

b

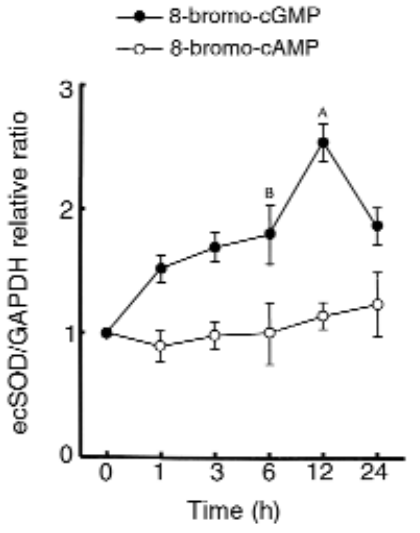

Figure 3

Effect of cAMP analogue 8-bromo-cAMP $(100 \mu \mathrm{M})$ and cGMP analogue 8-bromo-cGMP $(100 \mu \mathrm{M})$ on ecSOD mRNA expression in HASMs. HASMs (passages 4-8) were exposed to either 8-bromocAMP $(100 \mu \mathrm{M})$ or 8-bromo-cGMP $(100 \mu \mathrm{M})$ for the times indicated. (a) A representative RNase protection assay. (b) Mean data quantified by densitometry, expressed as a fold increase in ecSOD expression. Values are the mean $\pm \mathrm{SE}$ for three separate experiments. ${ }^{A} P<0.01 ;{ }^{B} P<0.05$ versus control cells.
$\mathrm{NO} \bullet$ has been shown to activate both $\mathrm{p} 42 / 44$ and $\mathrm{p} 38$ MAP kinases in various cell types (19-23). To examine a role for these in the upregulation of ecSOD by NO*, HASMs were incubated with either the MEK-inhibitor PD 98069 or the specific p38 MAP kinase inhibitor SB 230580 for 1 hour before addition of DETA-NO. SB $230580(10 \mu \mathrm{M})$ completely prevented the increase of ecSOD mRNA in response to DETA-NO (Figure 4). In additional experiments, another p38MAP kinase inhibitor, PD169316, also significantly inhibited the effect of DETA-NO on ecSOD mRNA expression (data not shown). In contrast, the MEK-inhibitor PD 98069 $(30 \mu \mathrm{M})$ had no effect (Figure 4).

To determine directly whether NO could activate p38MAP kinase, HASMs at $80-90 \%$ confluence in $100-$ $\mathrm{mm}$ dishes were made quiescent by incubation with Smooth Muscle Basal Medium and 0.5\% FBS for 24 hours. HASMs were then either not treated or exposed to $100 \mu \mathrm{M}$ DETA-NO at $37^{\circ} \mathrm{C}$ in serum-free medium for 60 minutes, and Western analyses were performed to detect phospho-p38MAP kinase. As is evident in Figure 4c, DETA-NO treatment increased phosphorylation of p38MAP kinase by $10.2 \pm 1$ fold $(n=3)$ (Figure 4c).

Effect of $N O$ on ecSOD transcription rate and $m R N A$ stability in HASMs. An increase in ecSOD mRNA could reflect either an increase in the rate of transcription or a decrease in the rate of mRNA decay, or both. Additional experiments were performed to examine these possibilities. For nuclear run-on studies, 50 million nuclei were harvested from HASMs under control conditions and followed by 4 hours exposure to $100 \mu \mathrm{M}$ DETA-NO. These assays revealed that DETA-NO increased the transcription rate by $2.3 \pm 0.2$ fold (Figure 5a). To examine ecSOD mRNA stability, HASMs
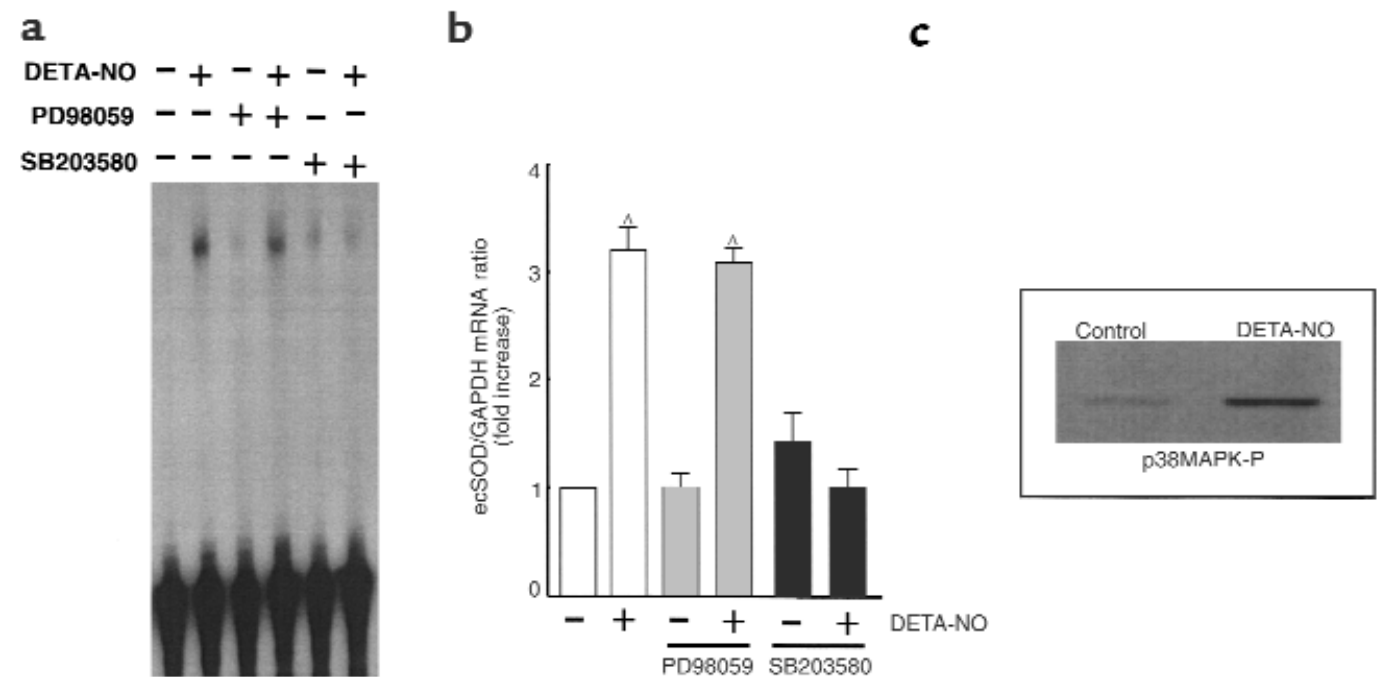

\section{Figure 4}

Evidence for a role of $38 \mathrm{MAP}$ kinase in modulation of ecSOD expression by NO. HASMs were exposed to DETA-NO (100 $\mu$ M) for 12 hours in the absence or presence of the various antagonists noted ( $\mathbf{a}$ and $\mathbf{b}$ ), or for 60 minutes (c). (a) A representative RNase protection assay. (b) Mean values of densitometric analysis. (c) A representative Western analysis for P38MAP kinase phosphorylation by $100 \mu \mathrm{M}$ DETA-NO $(n=3)$. HASMs were treated with DETA-NO for 1 hour before harvest. Western analysis was performed using a specific anti-phospho p38MAP kinase ( 338 MAPK-P) antibody. Values are the mean \pm SE for three separate experiments. ${ }^{A} P<0.01$ versus control cells. 
a

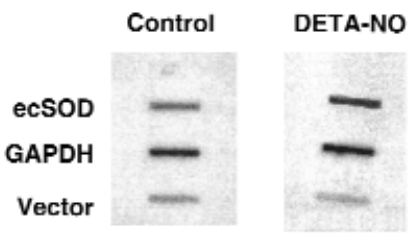

b

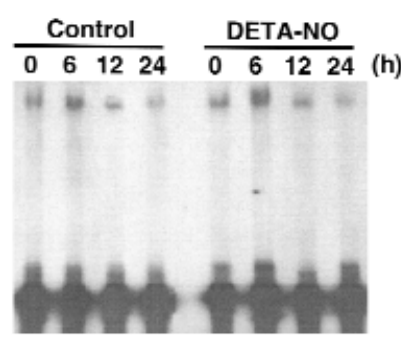

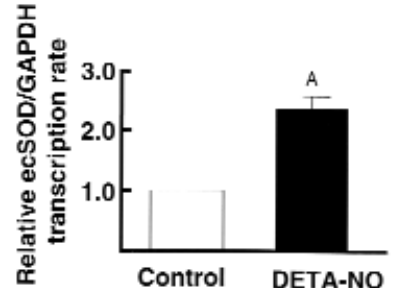

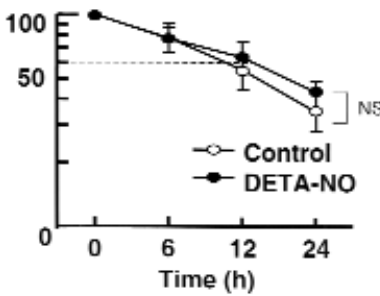

Figure 5

Effect of DETA-NO $(100 \mu \mathrm{M})$ on ecSOD transcription rate and mRNA stability in HASMs. For nuclear-run on studies, nuclei were harvested from HASMs under control conditions and after 4 hours of exposure to DETANO. For mRNA stability, HASMs were exposed to either control conditions or DETA-NO for 10 hours and then exposed to actinomycin $\mathrm{D}(10 \mu \mathrm{g} / \mathrm{mL})$. Messenger RNA levels were determined using RNase protection assays as shown in Figures 5 through 8. For both panels, the left portion shows representative experiment, whereas the right panel shows mean data for three (a) and four (b) separate experiments. Mean data in $\mathbf{b}$ are expressed as a percent of mRNA at time $0 .{ }^{A} P<0.05$ versus control cells. NS, not significant. were either not treated or were pretreated with $100 \mu \mathrm{M}$ DETA-NO for 10 hours and then exposed to $10 \mu \mathrm{g} / \mathrm{mL}$ actinomycin D for 6-24 hours. Total RNA was collected at the times indicated, and RNase protection assays were performed as already described here. These studies showed that DETA-NO had no effect on the halflife of ecSOD mRNA (Figure 5b). Taken together, these experiments suggest that the major effect of NO on ecSOD expression is mediated through an increase in mRNA transcription.

Effect of $N O$ on ecSOD expression in organoid culture of mouse aortas. Vascular smooth muscle cells in culture acquire a synthetic phenotype and often exhibit responses to physical and humoral stimuli not observed when cells are in the contractile phenotype (11). To eliminate the possible involvement of these factors, we used organoid cultures of mouse aorta $(14,15)$. Western blots consistently revealed two bands in mouse aortas corresponding to ecSOD types $\mathrm{C}$ and $\mathrm{A}$ (proteolized form). Exposure of mouse aortas to $100 \mu \mathrm{M}$ DETA-NO increased ecSOD protein levels in a time-dependent fashion. By 12 hours of exposure to DETA-NO, ecSOD protein increased by $3.2 \pm 0.3$ fold (Figure 6a). Furthermore, this response was also dose dependent (Figure 6b). These studies show that $\mathrm{NO} \cdot$ not only increases ecSOD expression in cultured human smooth muscle cells, but also in intact vascular segments.

To determine whether the increase in ecSOD protein expression was accompanied by an increase in ecSOD activity, SOD assays were performed. Aortas of C57BL/6 mice were placed in organoid culture system with and without $100 \mu \mathrm{M}$ DETA-NO treatment for 24 hours and then homogenized. Treatment with DETANO approximately doubled ecSOD activity, whereas it had no effect on the other SOD isozymes (Figure 7). Thus, the increase in ecSOD protein expression is associated with an increase in ecSOD enzymatic function. a
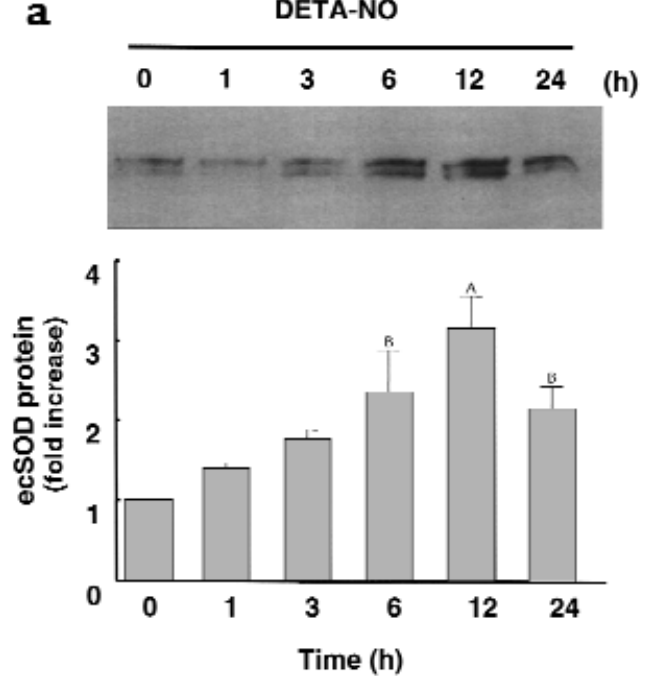

b

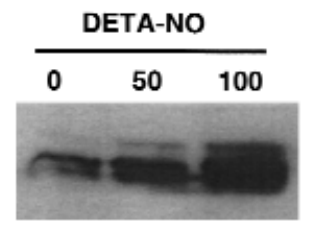

$(\mu \mathrm{M})$

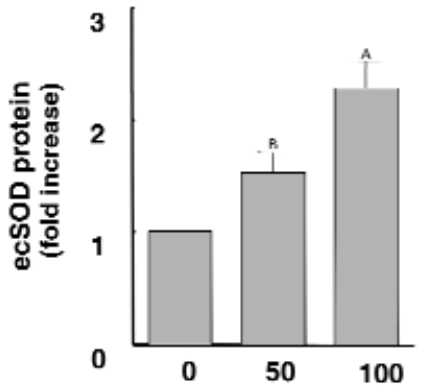

$(\mu \mathrm{M})$

\section{Figure 6}

Time course and dose response of ecSOD protein expression in response to DETA-NO on mouse aortas in organoid culture. Vessels were placed in organoid culture and exposed to DETANO for the times (a) and the concentrations (b) indicated. Expression of ecSOD protein was examined using Western analysis. The upper panel shows a representative Western analysis, whereas the bottom panels depict mean values for four separate experiments. ${ }^{A} P<0.01$; ${ }^{B} P<$ 0.05 versus control cells. 
Total SOD

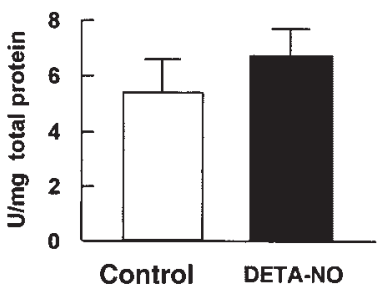

Cu/ZnSOD

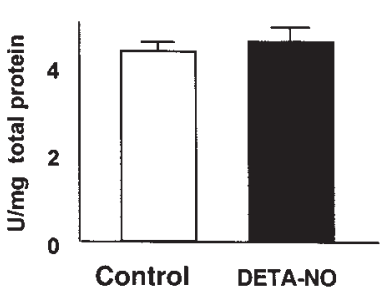

Figure 7

Total SOD activity and activities of individual SOD subtypes in response to DETA-NO $(100 \mu \mathrm{M})$ on mouse aortas $(\mathrm{C} 57 \mathrm{BL} / 6)$ in organoid culture. Aortas were homogenized, and SOD activity was assayed by examining inhibition cytochrome $\mathrm{c}$ reduction by xanthine/xanthine oxidase at $\mathrm{pH}$ 7.4. The activity of MnSOD was examined by addition of KCN ( $3 \mathrm{mM})$. The activity of ecSOD was determined after separation with Con A-Sepharose. Experiments were performed on four pooled aortas on three separate occasions. The results are presented as mean \pm SEM, and the values are expressed as units per milligram of total protein. ${ }^{A} P<0.05$ versus control cells.

SOD expression in mouse aorta from C57BL/6 and $\mathrm{NOS}^{-/-}$mice. To examine the physiological role of $\mathrm{NO}$ in regulating vascular ecSOD expression in vivo, studies using eNOS ${ }^{-/-}$mice were performed. Protein levels of ecSOD were substantially decreased in aortas from both strain A (56 $\pm 1 \%$ fold decrease) and strain B (38 \pm $1 \%$ fold decrease) eNOS $-1-$ mice compared with aortas from control C57BL/6 mice (Figure 8). In contrast, $\mathrm{Cu} / \mathrm{ZnSOD}$ expression was not changed in aorta from both strain of eNOS $^{-/-}$mice.

Effect of exercise training on ecSOD protein expression in aortas of $\mathrm{C} 57 \mathrm{BL} / 6$ mice and $\mathrm{eNOS}^{-/-}$mice. Previous studies in both experimental animals and humans have shown that exercise training increases the expression of eNOS. If endogenous NO modulates ecSOD expression, we reasoned that exercise would increase not only eNOS, but also ecSOD expression through the mechanisms dependent on endothelium-derived NO. We therefore trained both control C57BL/6 mice and $\mathrm{eNOS}^{-/-}$mice at submaximal levels for 3 weeks. Both groups successfully completed the training protocols. Three weeks of treadmill training increased eNOS expression in C57BL/ 6 mouse aortas by $3.2 \pm 0.5$ fold (Figure 9, $\mathrm{a}$ and $\mathrm{b}$ ). In parallel with this, the expression of ecSOD protein was also increased by $2.8 \pm 0.4$ fold, whereas aortic $\mathrm{Cu} / \mathrm{ZnSOD}$ protein levels were not changed by training. In striking contrast to these results in control mice, exercise training had no effect on ecSOD protein levels in $\mathrm{eNOS}^{-/-}$mice.

\section{Discussion}

The present study demonstrates that NO modulates the expression of ecSOD in vascular smooth muscle cells in culture and seems to be a critical determinant of expression of vascular ecSOD in vivo. This effect of NO is mediated via the cGMP/protein kinase G-dependent pathway. In blood vessels, the major source of ecSOD is vascular smooth muscle cells. Thus, this long-term paracrine effect of $\mathrm{NO}$ released from the endothelium on gene expression in smooth muscle seems analogous to the acute role of endothelium-derived NO in producing vasodilatation of the adjacent vascular smooth muscle via the same $\mathrm{CGMP} /$ protein kinase $\mathrm{G}$ pathway. This long-term effect of NO is dependent on p38 MAP kinase and is mediated by an increase in ecSOD transcriptional rate. Importantly, this is the first demonstration that ecSOD expression is increased by exercise. This phenomenon is likely an important molecular adaptation to exercise training that ultimately modulates vascular redox state in a favorable fashion.

It has recently been shown that vascular cells can release $\mathrm{O}_{2}{ }^{--}$extracellularly (24) and that this production of $\mathrm{O}_{2}{ }^{-}$can modulate levels of $\mathrm{NO}^{\bullet}$, as these molecules undergo an extremely rapid, diffusion limited radical/radical reaction, leading to the formation of nitrite, nitrate, and very importantly, the peroxynitrite anion $(25,26)$. The upregulation of ecSOD in response

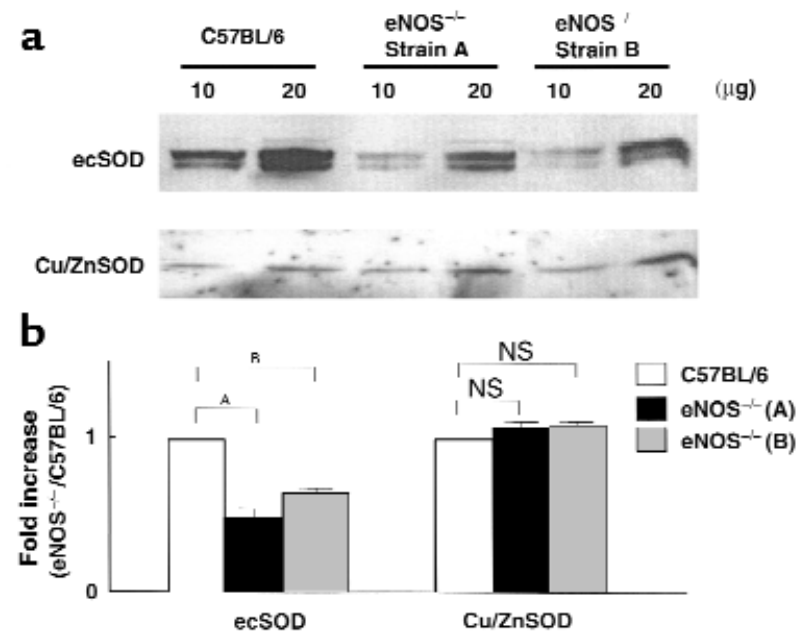

Figure 8

Western analysis of ecSOD protein in aortas of C57BL/ 6 and endothelial NO synthase (eNOS) $)^{-1-}$ mice. (a) Representative Western blots for control the eNOS ${ }^{-/}$mice. Ten and $20 \mu \mathrm{g}$ of protein from tissue homogenates of aortas of both $\mathrm{C} 57 \mathrm{BL} / 6$ and $\mathrm{eNOS}^{-/-}$mice were loaded in adjacent lanes and size separated on SDS gel. After transfer to a nitrocellulose membrane, ecSOD and $\mathrm{Cu} / \mathrm{ZnSOD}$ proteins were detected by immunoblotting with their respective antibodies. (b) Densitometric analysis of Western blots for ecSOD protein and $\mathrm{Cu} / \mathrm{ZnSOD}$ protein expression in control and $\mathrm{eNOS}^{-/-}$mice. Data are mean $\pm \mathrm{SEM}$ ( $n=5$ for both groups). ${ }^{\mathrm{A}} P<0.01 ;{ }^{\mathrm{B}} P<0.05$ versus control cells. 
a

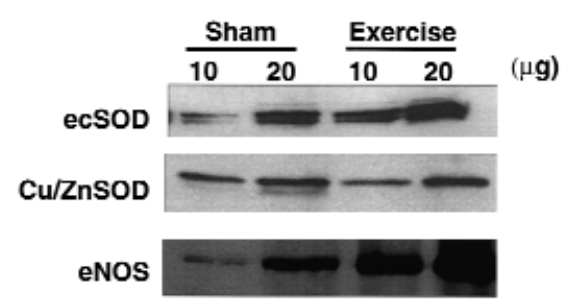

b

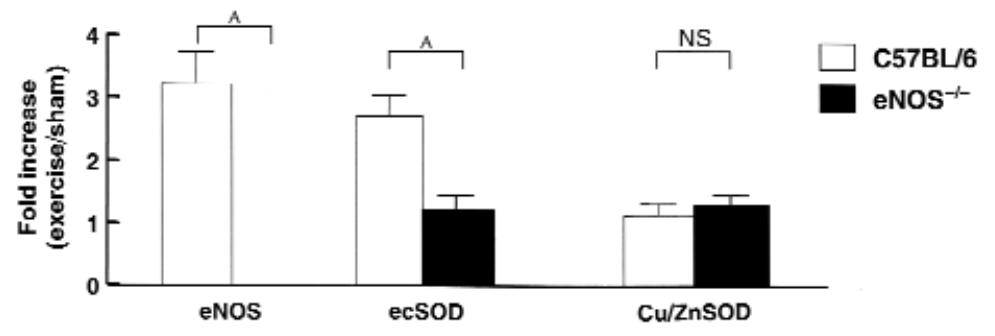

\section{Figure 9}

Effect of 3 weeks of exercise training on ecSOD, $\mathrm{Cu} / \mathrm{ZnSOD}$, and eNOS protein expression in aortas of $\mathrm{C} 57 \mathrm{BL} / 6$ mice and eNOS ${ }^{-1-}$ mice. (a) Western analysis of ecSOD protein, $\mathrm{Cu} / \mathrm{ZnSOD}$ protein, and eNOS protein in aortas of $\mathrm{C} 57 \mathrm{BL} / 6$ and $\mathrm{eNOS}^{-/-}$mice. Both untrained (sham) mice and mice exposed to 3 weeks of exercise training were studied. Twenty micrograms of mouse aorta from C57BL/ 6 was used as a positive control (PC). Western analyses were performed as described in Figure 6. (b) Densitometric analysis of a. Data are mean \pm SEM for $n=6(\mathrm{C} 57 \mathrm{BL} / 6)$ and $n=3$ $\left(\mathrm{eNOS}^{-/-}\right.$mice [strain A]). The data from eNOS $^{-/-}$strain B mice $(n=3)$ showed similar results. ${ }^{A} P<0.01$ versus control cells. to $\mathrm{NO}^{\bullet}$ would reduce reactions of $\mathrm{NO}^{\bullet}$ with $\mathrm{O}_{2}{ }^{\bullet}$, thereby enhancing the biologic effects of $\mathrm{NO}^{\bullet}$ released by the endothelium. Of interest, immunohistochemical studies have shown that vascular ecSOD is localized in high concentrations between the endothelium and the smooth muscle, where endothelium-derived NO must transverse to stimulate smooth muscle relaxation (27). Thus, regulation of ecSOD expression by NO very likely represents an important feed-forward mechanism, whereby $\mathrm{NO}^{\bullet}$ released from the endothelium ultimately enhances its own biologic effect by reducing $\mathrm{O}_{2}{ }^{\bullet-}$ in this critical extracellular site.

NO exhibits its myriad of cellular effects though both cGMP-dependent and -independent mechanisms. Examples of cGMP-dependent mechanisms include upregulation of transcription of c-fos, c-jun B $(28,29)$, and the ETA receptor (30). In contrast, $\mathrm{NO}$ inhibits $\mathrm{NF} \mathrm{kB}$ binding $(31,32)$ and reduces expression of both the angiotensin II type I receptor (33) and heme oxygenase-1 (34) via cGMP-independent processes. The effect of $\mathrm{NO}$ on ecSOD expression seems entirely cGMP dependent, as it was completely prevented by the selective guanylate cyclase inhibitor ODQ and was mimicked by a membrane-permeable cGMP analogue, $8 \mathrm{Br}$-cGMP. A major cellular target of cGMP is protein kinase $\mathrm{G}$, which appears also to be importantly involved in this response, as Rp-8-CPT-cGMPs completely prevented the increase in ecSOD mRNA by DETA-NO. cGMP has also been shown to activate protein kinase A (PKA; 35, 36); however, PKA is unlikely involved, as 8-bromo-cyclic AMP had no effect on ecSOD mRNA expression.

Importantly, two specific p38MAP kinase inhibitors, PD169316 and SB203580, both pyridinyl imidazole compounds, completely inhibited the upregulation of ecSOD by DETA-NO in HASM, whereas the p42/44MAP kinase kinase inhibitor, PD98059, had no effect. Furthermore, using Western analysis for phospho-p38 MAP kinase, we were able to demonstrate that
DETA-NO activated p38MAP kinase in HASMs. To our knowledge, this is the first evidence that p38MAP kinase is activated by $\mathrm{NO}$ in vascular smooth muscle cells. Consistent with our findings, activation of p38MAP kinase by NO has been observed in Jurkat T cells (19), human neutrophils (20), human fibroblasts (21) and rat renal mesangial cells (22). In particular, Browning et al. $(20,21)$ have recently shown that NO activates p38MAP kinase via cGMP dependent mechanisms in human neutrophils and 293T fibroblasts. Taken together, our evidence and the existing literature suggest a role of p38MAP kinase as a downstream target of the $\mathrm{cGMP} /$ protein kinase $\mathrm{G}$ pathway.

Actinomycin D studies and nuclear run-on assays showed that the upregulation of ecSOD by NO mainly occurred at the level of ecSOD gene transcription. It has been reported that NO increases transcription of a variety of genes via cGMP-dependent mechanisms (28-30) and that several transcription factors, including NF-kB (31, 32), AP-1 (28), Sp-1 (37), heat shock factor 1 (38), and Oct-1 (39) can be activated by NO. Of note, Pilts et al. (28) have demonstrated that NO stimulates gene transcription via an AP-1 consensus sequence element through a cGMP-dependent pathway. Recently, the transcription factors ATF-2 (40) and MEF2C (41) have been shown to be substrates of p38MAP kinase and to be involved in AP-1 activation $(42,43)$. Importantly, the promoter of the ecSOD gene contains an AP-1 consensus sequence -397 bp upstream of the transcription start site (44), raising the possibility that cGMP- and p38MAP kinase-dependent pathways may converge at the levels of AP-1 activation.

To gain insight further into the role of endogenous $\mathrm{NO}$ in ecSOD expression in vivo, we studied both normal and eNOS $-/-$ mice. At baseline, the $\mathrm{eNOS}^{-/-}$mice demonstrated a markedly depressed expression of ecSOD, strongly suggesting that endothelium-derived NO modulates ecSOD expression in vivo. This finding 
was unlikely due to an artifact caused by genetic manipulation, as it was observed in two separate strains of $\mathrm{eNOS}^{-/-}$mice, produced by deletion of different eNOS exons. We further examined the role of $\mathrm{NO}$ in modulating vascular ecSOD during exercise training. Three weeks of treadmill exercise training dramatically increased eNOS protein level by about threefold in aortas of control mice. This result is similar to previous findings by Sessa et al. (9) who demonstrated that 10 days of treadmill exercise training enhanced aortic and coronary eNOS gene expression. Likewise, in humans with heart failure, exercise training increases flow-mediated vasodilatation of the brachial artery (45). In our present study, in parallel with the increase in eNOS expression, we found that exercise training also increased ecSOD expression by about threefold. Importantly, this upregulation of ecSOD expression by exercise was not observed in aortas from $\mathrm{eNOS}^{-/-}$mice. These findings strongly suggest that endogenous NO potently modulates the expression of ecSOD in vivo, both under basal conditions and in response to exercise training.

In a previous study, we have found that exposure of cultured endothelial cells to shear stress dramatically increases expression of the cytosolic $\mathrm{Cu} / \mathrm{ZnSOD}$ (16). In this prior study, we found that shear stress had no effect on expression of $\mathrm{Cu} / \mathrm{ZnSOD}$ in human aortic smooth muscle cells. Our current findings show that mechanical influence likely has at least two important effects on SOD levels in vivo. The direct effect of shear stress increases $\mathrm{Cu} / \mathrm{ZnSOD}$ expression in endothelial cells, and the indirect effect of NO released in response to mechanical stimuli, as present during exercise training, increases expression of ecSOD in vascular smooth muscle cells.

Of note, exercise increases total body oxygen uptake, and acute bouts of exercise increase oxidant stress (10), increasing the susceptibility of plasma LDL to oxidation (46) and increasing conjugated diene formation (47). Furthermore, endothelial shear stress (increased during bouts of exercise) has been shown to stimulate vascular superoxide production (48). An increase in expression of ecSOD would represent an important physiological adaptation that would counteract this increase in oxidant stress in response to exercise training.

In the present study, we used a submaximal exercise training level, and both the control and eNOS-deficient mice were able to complete the training protocol. We did not determine whether the eNOS-deficient mice could train at a more nearly maximal level, or if their ultimate aerobic capacity was impaired compared with the control mice. However, Maxwell et al. have shown that training capacity is impaired in mice treated with nitro L-arginine, which inhibits NOS (49). Our findings regarding an impairment of ecSOD expression in response to exercise in eNOS-deficient mice might explain one of the mechanisms by which this happens.

Our current findings may also have implications for pathophysiological situations. Numerous conditions, including atherosclerosis, aging, cigarette smoking, and diabetes are associated with a decline in the pro- duction and/or biologic activity of endotheliumderived $\mathrm{NO}^{\bullet}(50)$. In these conditions, the loss of $\mathrm{NO}$ may lead to a decline in ecSOD expression, as we observed in eNOS-deficient mice. Indeed, in Apo (E)-deficient mice, we have previously found that the vascular smooth muscle cell expression of ecSOD declines as the severity of atherosclerosis increases (15). Landmesser et al. have recently shown that plasma levels of ecSOD are markedly reduced in individuals with advanced atherosclerosis (51). One explanation for these findings is that atherosclerosis is associated with a loss of endothelium-derived NO production and/or bioreactivity, leading to a decrease in ecSOD expression. It is interesting to speculate that other conditions associated with a long-term loss of NO would also decrease expression of ecSOD, adversely impacting the vascular redox state.

It is important to consider our present findings in perspective with current clinically employed therapies. One therapeutic approach has been to attempt to modify vascular redox state via administration of oral antioxidant agents. The rate constants for reactions of vitamins $\mathrm{E}$ and $\mathrm{C}$ with superoxide are on the order of $10^{5} / \mathrm{M} / \mathrm{s}(52)$. In contrast, the rate constant for the reaction of $\mathrm{O}_{2}{ }^{-}$with SOD is about $1.210^{9} / \mathrm{M} / \mathrm{s}$. Given these considerations, it is likely that the tripling in ecSOD resulting from exercise training has a much greater effect on vascular scavenging of $\mathrm{O}_{2}{ }^{-}$than would treatment with reasonable concentrations of antioxidant vitamins. Further, it is likely that the beneficial effect of exercise training on endothelium-dependent vasodilatation observed in several studies $(45,53)$ is not only due to an increase in expression of eNOS, but also due to an increase in ecSOD expression, which serves to minimize reactions of $\mathrm{O}_{2}{ }^{-}$- with $\mathrm{NO}^{*}$. These experiments therefore provide an important new mechanism whereby exercise training may benefit vascular function. Whether or not a similar increase in ecSOD expression could be obtained in vivo by treatment with organic nitrates or other NO donors remains to be determined, but may represent an important therapeutic direction.

\section{Acknowledgments}

The authors thank P.L. Huang for providing eNOS-/strain A) mice. Supported by NIH RO-1 HL39006, NIH RO-1 HL59248, Program Project grant HL5800, and a VA Merit grant.

\footnotetext{
1. Knowles, R.G., and Moncada, S. 1994. Nitric oxide synthases in mammals. Biochem. J. 298:249-258.

2. Fridovich, I. 1997. Superoxide anion radical $\left(\mathrm{O}_{2}{ }^{-}\right)$, superoxide dismutases, and related matters. J. Biol. Chem. 272:18515-18517.

3. Strålin, P., Karlsson, K., Johansson, B.O., and Markland, S.L. 1995. The interstitium of the human arterial wall contains very large amounts of extracellular superoxide dismutase. Arterioscler. Thromb. Vasc. Biol. 15:2032-2036.

4. Hatori, N., Sjoquist, P.O., Marklund, S.L., and Ryden, L. 1992. Effects of recombinant human extracellular-superoxide dismutase type $\mathrm{C}$ on myocardial infarct size in pigs. Free Radic. Biol. Med. 13:221-230.

5. Fukui, T., et al. 1997. p22phox mRNA expression and NADPH oxidase activity are increased in aortas from hypertensive rats. Circ. Res. 80:45-51. 6. Ekelund, L.G., et al. 1988. Physical fitness as a predictor of cardiovascular mortality in asymptomatic North American men. The Lipid Research
} 
Clinics Mortality Follow-up Study. N. Engl. J. Med. 319:1379-1384.

7. Paffenbarger, R.S., Jr., et al. 1993. The association of changes in physicalactivity level and other lifestyle characteristics with mortality among men. N. Engl. J. Med. 328:538-545.

8. Blair, S.N., et al. 1995. Changes in physical fitness and all-cause mortality. A prospective study of healthy and unhealthy men. JAMA. 273:1093-1098.

9. Sessa, W.C., Pritchard, K., Seyedi, N., Wang, J., and Hintze, T.H. 1994. Chronic exercise in dogs increases coronary vascular nitric oxide production and endothelial cell nitric oxide synthase gene expression. Circ. Res. 74:349-353.

10. Ji, L.L. 1999. Antioxidants and oxidative stress in exercise. Proc. Soc. Exp. Biol. Med. 222:283-292.

11. Lincoln, T.M., Dey, N.B., Boerth, N.J., Cornwell, T.L., and Soff, G.A. 1998. Nitric oxide-cyclic GMP pathway regulates vascular smooth muscle cell phenotypic modulation: implications in vascular diseases. Acta Physiol. Scand. 164:507-515.

12. Huang, P.L., et al. 1995. Hypertension in mice lacking the gene for endothelial nitric oxide synthase. Nature. 377:239-242.

13. Shesely, E., et al. 1996. Elevated blood pressures in mice lacking endothelial nitric oxide synthase. Proc. Natl. Acad. Sci. USA. 93:13176-13181.

14. Fukai, T., Siegfried, M.R., Ushio-Fukai, M., Griendling, K.K., and Harrison, D.G. 1999. Modulation of extracellular superoxide dismutase expression by angiotensin II and hypertension. Circ. Res. 85:23-28.

15. Fukai, T., Galis, Z.S., Meng, X.P., Parthasarathy, S., and Harrison, D.G. 1998. Vascular expression of extracellular superoxide dismutase in atherosclerosis. J. Clin. Invest. 101:2101-2111.

16. Inoue, N., Ramasamy, S., Fukai, T., Nerem, R.M., and Harrison, D.G. 1996. Shear stress modulates expression of $\mathrm{Cu} / \mathrm{Zn}$ superoxide dismutase in human aortic endothelial cells. Circ. Res. 79:32-37.

17. Ushio-Fukai, M., Alexander, R.W., Akers, M., and Griendling, K.K. 1998 p38 Mitogen-activated protein kinase is a critical component of the redox-sensitive signaling pathways activated by angiotensin II. Role in vascular smooth muscle cell hypertrophy. J. Biol. Chem. 273:15022-15029.

18. Lincoln, T.M., Cornwell, T.L., Komalavilas, P., and Boerth, N. 1996. Cyclic GMP-dependent protein kinase in nitric oxide signaling. Methods Enzymol. 269:149-166.

19. Lander, H.M., Jacovina, A.T., Davis, R.J., and Tauras, J.M. 1996. Differential activation of mitogen-activated protein kinases by nitric oxiderelated species. J. Biol. Chem. 271:19705-19709.

20. Browning, D.D., Windes, N.D., and Ye, R.D. 1999. Activation of p38 mitogen-activated protein kinase by lipopolysaccharide in human neutrophils requires nitric oxide-dependent cGMP accumulation. J. Biol. Chem. 274:537-542.

21. Browning, D.D., McShane, M.P., Marty, C., and Ye, R.D. 2000. Nitric oxide activation of p38 mitogen-activated protein kinase in 293T fibroblasts requires cGMP-dependent protein kinase. J. Biol. Chem. 275:2811-2816.

22. Huwiler, A., and Pfeilschifter, J. 1999. Nitric oxide stimulates the stressactivated protein kinase p38 in rat renal mesangial cells. J. Exp. Biol. 202:655-660.

23. Callsen, D., Pfeilschifter, J., and Brune, B. 1998. Rapid and delayed p42/p44 mitogen-activated protein kinase activation by nitric oxide: the role of cyclic GMP and tyrosine phosphatase inhibition. J. Immunol. 161:4852-4858

24. Souchard, J.P., et al. 1998. Electron spin resonance detection of extracellular superoxide anion released by cultured endothelial cells. Free Radic. Res. 29:441-449.

25. Beckman, J.S., Beckman, T.W., Chen, J., Marshall, P.A., and Freeman, B.A. 1990. Apparent hydroxyl radical production by peroxynitrite: implications for endothelial injury from nitric oxide and superoxide. Proc. Natl. Acad. Sci. USA. 87:1620-1624.

26. Darly-Usmar, V.M., Hogg, N., O’Leary, V.J., Wilson, M.T., and Moncada, S. 1992. The simultaneous generation of superoxide and nitric oxide can initiate lipid peroxidation in human low density lipoprotein. Free Rad. Res. Commun. 17:9-20.

27. Oury, T.D., Day, B.J., and Crapo, J.D. 1996. Extracellular superoxide dismutase: a regulator of nitric oxide bioavailability. Lab. Invest. 75:617-636

28. Pilz, R.B., Suhasini, M., Idriss, S., Meinkoth, J.L., and Boss, G.R. 1995. Nitric oxide and cGMP analogs activate transcription from AP-1-responsive promoters in mammalian cells. FASEB J. 9:552-558.

29. Haby, C., Lisovoski, F., Aunis, D., and Zwiller, J. 1994. Stimulation of the cyclic GMP pathway by NO induces expression of the immediate early genes c-fos and jun B in PC12 cells. J. Neurochem. 62:496-501.
30. Redmond, E.M., Cahill, P.A., Hodges, R., Zhang, S., and Sitzmann, J.V. 1996. Regulation of endothelin receptors by nitric oxide in cultured rat vascular smooth muscle cells. J. Cell. Physiol. 166:469-479.

31. Lander, H.M., Sehajpal, P., Levine, D.M., and Novogrodsky, A. 1993. Activation of human peripheral blood mononuclear cells by nitric oxide-generating compounds. J. Immunol. 150:1509-1516.

32. Peng, H.B., Rajavashisth, T.B., Libby, P., and Liao, J.K. 1995. Nitric oxide inhibits macrophage-colony stimulating factor gene transcription in vascular endothelial cells. J. Biol. Chem. 270:17050-17055.

33. Ichiki, T., et al. 1998. Downregulation of angiotensin II type 1 receptor gene transcription by nitric oxide. Hypertension. 31:342-348.

34. Durante, W., Kroll, M.H., Christodoulides, N., Peyton, K.J., and Schafer, A.I. 1997. Nitric oxide induces heme oxygenase-1 gene expression and carbon monoxide production in vascular smooth muscle cells. Circ. Res. 80:557-564.

35. Cornwell, T.L., Arnold, E., Boerth, N.J., and Lincoln, T.M. 1994. Inhibition of smooth muscle cell growth by nitric oxide and activation of CAMPdependent protein kinase by cGMP. Am. J. Physiol. 267:C1405-C1413.

36. Jiang, H., Colbran, J.L., Francis, S.H., and Corbin, J.D. 1992. Direct evidence for cross-activation of cGMP-dependent protein kinase by cAMP in pig coronary arteries. J. Biol. Chem. 267:1015-1019.

37. Wang, S., Wang, W., Wesley, R.A., and Danner, R.L. 1999. A Sp1 binding site of the tumor necrosis factor alpha promoter functions as a nitric oxide response element. J. Biol. Chem. 274:33190-33193.

38. Xu, Q., Hu, Y., Kleindienst, R., and Wick, G. 1997. Nitric oxide induces heat-shock protein 70 expression in vascular smooth muscle cells via activation of heat shock factor 1. J. Clin. Invest. 100:1089-1097.

39. Liu, X.K., Abernethy, D.R., and Andrawis, N.S. 1998. Nitric oxide inhibits Oct-1 DNA binding activity in cultured vascular smooth muscle cells. Life Sci. 62:739-749.

40. Raingeaud, J., Whitmarsh, A.J., Barrett, T., Derijard, B., and Davis, R.J. 1996. MKK3- and MKK6-regulated gene expression is mediated by the p38 mitogen-activated protein kinase signal transduction pathway. Mol. Cell. Biol. 16:1247-1255.

41. Han, J., Jiang, Y., Li, Z., Kravchenko, V.V., and Ulevitch, R.J. 1997. Activation of the transcription factor MEF2C by the MAP kinase p38 in inflammation. Nature. 386:296-299.

42. Whitmarsh, A.J., and Davis, R.J. 1996. Transcription factor AP-1 regulation by mitogen-activated protein kinase signal transduction pathways. J. Mol. Med. 74:589-607.

43. Kyriakis, J.M. 1999. Activation of the AP-1 transcription factor by inflammatory cytokines of the TNF family. Gene Expr. 7:217-231.

44. Folz, R.J., and Crapo, J.D. 1994. Extracellular superoxide dismutase (SOD3): tissue-specific expression, genomic characterization, and computer-assisted sequence analysis of the human EC SOD gene. Genomics. 22:162-171

45. Hornig, B., Maier, V., and Drexler, H. 1996. Physical training improves endothelial function in patients with chronic heart failure. Circulation. 93:210-214

46. Shern-Brewer, R., Santanam, N., Wetzstein, C., White-Welkley, J., and Parthasarathy, S. 1998. Exercise and cardiovascular disease: a new perspective. Arterioscler. Thromb. Vasc. Biol. 18:1181-1187.

47. Sanchez-Quesada, J.L., et al. 1995. Increase of LDL susceptibility to oxidation occurring after intense, long duration aerobic exercise. Atherosclerosis. 118:297-305.

48. De Keulenaer, G.W., et al. 1998. Oscillatory and steady laminar shear stress differentially affect human endothelial redox state: role of a superoxide-producing NADH oxidase. Circ. Res. 82:1094-1101.

49. Maxwell, A.J., Schauble, E., Bernstein, D., and Cooke, J.P. 1998. Limb blood flow during exercise is dependent on nitric oxide. Circulation. 98:369-374.

50. Harrison, D.G. 1997. Cellular and molecular mechanisms of endothelial cell dysfunction. J. Clin. Invest. 100:2153-2157.

51. Landmesser, U., et al. 2000. Vascular extracellular superoxide dismutase activity in patients with coronary artery disease-relation to endothelium-dependent vasodilation. Circulation.101:2264-2270.

52. Darley-Usmar, V., Wiseman, H., and Halliwell, B. 1995. Nitric oxide and oxygen radicals: a question of balance. FEBS Lett. 369:131-135.

53. Higashi, Y., et al. 1999. Regular aerobic exercise augments endotheliumdependent vascular relaxation in normotensive as well as hypertensive subjects: role of endothelium-derived nitric oxide. Circulation. 100:1194-1202. 